\title{
Visual arts and the teaching of the mathematical concepts of shape and space in Grade R classrooms
}

\author{
Dianne Wilmot, Rhodes University. * \\ Jean Schäfer, Rhodes University.
}

\begin{abstract}
This article addresses the need for research in the areas of Grade $R$ curriculum and pedagogy, Grade $R$ teacher professional development, and early years mathematics teaching. More specifically, it responds to the need for teacher professional development in Grade $R$ mathematics teaching of the geometric concepts of space and shape. The article describes a study about teachers' understanding of how visual arts can be used as pedagogical modality. The study was prompted by the findings of a 'Maths and Science through Arts and Culture Curriculum' intervention undertaken with Grade $R$ teachers enrolled for a Bachelor of Education (Foundation Phase) degree at a South African university. Post-intervention, teachers' classroom practices did not change, and they were not using visual arts to teach mathematical concepts. The lessons learned from the research intervention may contribute to the wider debate about Grade $R$ teaching and children's learning.
\end{abstract}

Key words: visual arts, constructivist learning theories, shape and space concepts, emergent curriculum, reflective practice, kindergarten geometry

*Email address: d.wilmot@ru.ac.za.

South African Journal of Childhood Education | 2015 5(1): 62-84 | ISSN: 2223-7674 |๔ UJ

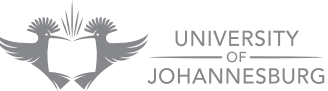




\section{Introduction}

From our experience of teaching and interacting with young children, we ${ }^{1}$ have been fascinated by how proficiently young children are able to show their understanding of the world around them through creative art activities. Einarsdottir, Dockett and Perry (2009) explain that, whereas often children's drawings and expressions of meaning through art are assessed according to the level of realism they display, more recently researchers have considered them instead as expressions of meaning and understanding. We are aware of how eager young children are to paint, cut and paste, model or draw to express their meanings and understandings when they are provided with a range of interesting materials and encouraged to use them across the curriculum in creative art activities. Whereas some classrooms are rich in children's expressions of their understandings, it is known that this may not be the norm in Grade R classes in South Africa.

As teacher educators, we have observed that creative art activities are not being used cross-curricularly in many Grade $\mathrm{R}$ classrooms and classroom displays show little evidence of children's expressions of their understandings and meanings, specifically as these pertain to children's concepts of shape and space. The provision of art materials may be a challenge in poorly resourced schools; however, we contend that a lack of resources is not the only reason why children are not being encouraged to express themselves through visual art. Teachers narrowly adhere to the national curriculum requirements. We have observed how children in Grade $\mathrm{R}$ classes spend more time completing worksheets than expressing their understandings through drawing and painting, which, we argue, can be an avenue of mathematical learning. The work of cognitive developmental psychologists such as Spelke and Lee (2012) show that young children's intuitive attraction to shapes is exemplified in their spontaneous drawings.

An interest in visual arts as a tool for enhanced learning was brought to the fore when the first author conducted an evaluation of the curriculum intervention programme Maths and Science through Arts and Culture (MStAC) that Grade R teachers studying towards an in-service BEd (Foundation Phase) degree at our university participated in. The findings of the evaluation (Schäfer 2009) showed that in spite of participating in the programme, the teachers did not use visual arts for children to express their understandings and for enhancing learning in mathematics and science when they returned to their classrooms. The evaluation study revealed that this was likely due to the Grade $\mathrm{R}$ teachers lacking the mathematical subject knowledge to do so; not understanding how children learn mathematics; lacking the confidence and ability to design appropriate activities; and not appreciating the significance of creativity in children's development and learning. This became the primary motivation for us wanting to answer the question: How can visual arts be used to teach the concepts of space and shape in Grade R?

In response to this question, we show how an intervention that adopts and models an emergent curriculum approach was used with the same group of Grade $R$ teachers with the aim of developing their understanding of creative art in the Grade $R$ 
curriculum, specifically with regard to informally teaching shape and space concepts. The intervention included the following: how to make meaning of children's interests as observed in their behaviour; how to plan activities around those interests; how to use visual arts to enable and support children's learning about space and shape; and how action research processes can promote teachers' development as reflective and reflexive practitioners. A secondary motivation was thus shaped by a transformational agenda, namely changing teachers' practice and enhancing teachers' competencies as reflective practitioners through classroom-based action research.

\section{Children's interests as the core curriculum}

The theoretical perspectives that informed the design of the intervention are drawn from both teacher development theory and some classical Piagetian notions of childhood learning.

The evaluation of the MStAC curriculum intervention (Schäfer 2009) convinced us that an innovative model of teacher professional development was required if the Grade $\mathrm{R}$ teachers were to transform their practice. We made the assumption that the teachers, through a particular research intervention, could learn how to build a curriculum around their children's interests, and thus be able to teach space and shape through visual arts experiences. The pedagogical challenge was thus to identify and implement strategies that would promote teachers' understanding of how children learn generally at this age; how children learn about space and shape specifically; how space and shape can be taught by means of a creative pedagogy; and how space and shape can be taught through visual arts in an emergent curriculum. By this we mean a curriculum that takes shape as it is implemented, specifically as a form of action research practice.

\section{A model of teacher professional development}

The design of the research intervention was guided by Borko and Putman's (1995) proposal that professional development requires instruction in three knowledge domains: general pedagogical knowledge, subject knowledge, and pedagogical content knowledge. This, together with the ideas and approaches to teacher professional development put forward by Hargreaves (1995); Lunenberg and Korthagen (2009); Mena Marcos, Sánchez and Tillema (2008); Mevarech (1995); Wilmot (2005); and Zeichner and Liston (1996), shaped the model used in the research intervention (Figure 1). 


\section{General pedagogical knowledge}

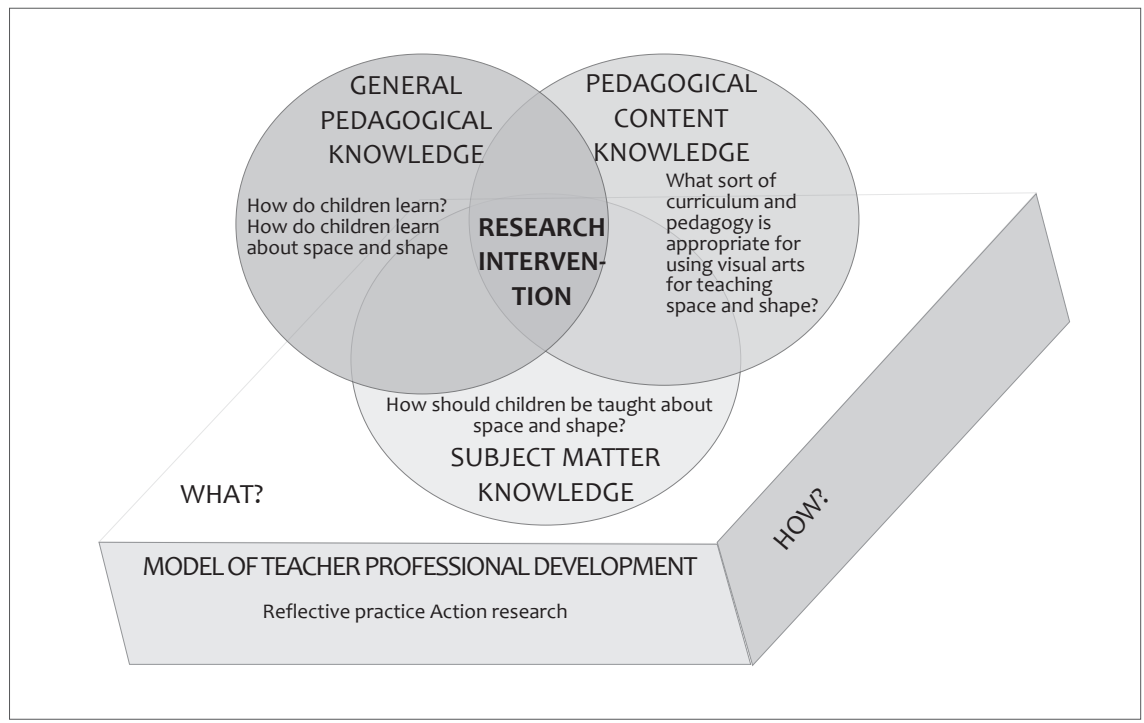

Figure 1: The model of teacher professional development underpinning the research intervention

Figure 1 shows the model of teacher professional development, which is based on reflective practice through an action research process. The three knowledge domains - general pedagogical knowledge, subject matter knowledge and pedagogical content knowledge (the 'what?') - intersect to form the research intervention, whilst the entire process rests on an action research process (the 'how?'). Borko and Putnam (1995) emphasise that the boundaries between these domains are indistinct, in that a teacher's knowledge and beliefs about how children learn are interconnected with knowledge of how to teach that subject. This is represented in Figure 1 by the overlapping areas of the circles showing the three types of knowledge proposed by Borko and Putnam (ibid) as necessary for teacher growth. Figure 1 also illustrates the areas of instruction according to the different knowledge domains: learning, space and shape, and pedagogy and curriculum.

\section{Learning in childhood}

As active learners, young children draw on "direct physical and social experience as well as culturally transmitted knowledge to construct their own understanding of the world around them" (NAEYC 1996:7). Theories of cognitive development help us to make sense of our observations of young children (Berk \& Winsler 1995; Berk 2006; Spelke \& Kinzler 2008; Spelke 2003). Recent cognitive neuroscience research has confirmed some of the notions and findings of constructivist cognitive theorists such as Piaget and Inhelder (1967) and Vygotsky (1978), and it has consequently also 
reaffirmed what is considered developmentally appropriate practice for teaching young children (Dehaene \& Brannon 2011; Gelman \& Butterworth 2005; NAEYC 1996; Rushton \& Larkin 2001).

\section{Space and shape conceptualisation}

When children arrive in Grade R classrooms, they already have certain informal mathematical ideas which are "surprisingly broad, complex and sometimes sophisticated" (Ginsburg, Lee \& Stevenson-Boyd 2008:3). Therefore, the sociocultural contexts of home learning should be valued, recognized and built upon (Carruthers \& Worthington 2006). It has been found that, from infanthood, children adopt schemas or spatial movement patterns as they experience the space around them. Piaget defined 'schemas' as cognitive structures that develop through interaction with the environment (Piaget \& Inhelder 1967), and Athey (2007) developed this definition further by defining children's actual movements in space, which, he argues, serve to represent their thoughts, whether by drawing certain objects or shapes, or by moving their bodies in particular ways. For the purposes of this article, we refer to schemas as Athey defines them. Gifford (2005:111) suggests “identifying and supporting children's schemas" in order to extend their learning about space and shape; in our intervention, this involved teaching the participant teachers how to identify children's schemas.

An understanding of shape follows a definite order, starting with physical manipulation of shapes (Gifford 2005; Piaget \& Inhelder 1967). The Van Hieles researched the development of children's understanding of shapes and identified five levels (Clements \& Battista 1992; Clements, Swaminathan, Hannibal \& Sarama 1999; Ryan \& Williams 2007), the first three of which are relevant to Grade R children. They are represented in table 1 below

Table 1: The first three Van Hiele levels of spatial understanding

\begin{tabular}{|l|l|}
\hline $\begin{array}{l}\text { Level } \mathbf{1} \text { (Visualisation and } \\
\text { recognition) }\end{array}$ & $\begin{array}{l}\text { Children are able to see that shapes are different, for example, a } \\
\text { square and a triangle, but cannot explain why they are different. }\end{array}$ \\
\hline Level 2 (Analysis) & Children are able to name the properties that make up shapes. \\
\hline Level 3 (Abstraction) & $\begin{array}{l}\text { Children can classify shapes according to their properties, for } \\
\text { example, a square is a type of rectangle. }\end{array}$ \\
\hline
\end{tabular}

If one argues along these developmental lines, children should therefore have many opportunities during the Grade $\mathrm{R}$ year to manipulate shapes, talk about them, classify them, learn vocabulary related to shapes, and construct with shapes in order to consolidate the learning that they bring to school and further extend their understanding and knowledge of shapes.

Children also need to develop spatial understanding in relation to themselves (position), and then in relation to objects surrounding them (location) (Dehaene \& Brannon 2011; Gifford 2005; Spelke 2011a). More recently, Dillon, Huang and Spelke (2013), and Spelke and Lee (2012), explained how navigating within a shape is innate to young babies and young children and forms the foundation of abstract geometry. 
As they develop, young children learn that shapes can be translated, so that they are further, closer, below or above; they can be reflected, so that they are symmetrical; they can be rotated; they can be changed so that they are bigger or smaller; or they can be seen from different perspectives. In this way, they learn to recognize a particular shape as a box, whether the box is near or far, tilted, or seen from above or below. Children bring their experiences and perceptions of space to the school environment. A curriculum of appropriate teaching and learning experiences will reinforce earlier experiences and enrich space and shape conceptualization.

Having outlined the theoretical perspectives we drew on to develop the Grade $R$ teachers' awareness and understanding of how cognition takes place and how an awareness and understanding of the concepts of space and shape develop, we now locate these ideas in the Grade $\mathrm{R}$ classroom.

\section{Pedagogy and an 'emergent' curriculum: How geometrical concepts come to the Grade R classroom}

Along with many contemporary theorists in the cultural historical and activity theory (CHAT) school of thought (Engeström 1999, 2007; Hedegaard 2007), Fleer (2010) argues that children's learning experiences have to be based within their sociocultural environments and that their prior experiences have to be recognised in order for to them to learn in school. This requires that a curriculum should not be cast in stone and continue to have an 'emergent' character. We argue that this type of emergent curriculum can only be realised in an environment where individual creativity is valued and supported.

Stacey (2009), building on the ideas of early years experts (Carruthers \& Worthington 2006; Ginsburg et al 2008; Pound 2003), suggests that an emergent curriculum should start with teachers closely observing children's play interests and interactions. Stacey also supports the idea of building on the child's experiences by using an emergent curriculum that is "framed by the teacher [but] child initiated" (Stacey 2009:17). 'Sustained shared thinking' (SST) (Siraj-Blatchford 2009) and scaffolding or mediating learning are central to an emergent curriculum. In practice, this means that "the teacher takes on the role of facilitator, taking what is seen and heard and bringing to children the opportunity to discover more, dig deeper, and construct further knowledge" (Stacey 2009:17). The teacher makes meaning of her observations, makes decisions about the curriculum, and plans the next steps, which support and extend the children's learning. Finally she reflects, responds and researches further before starting the cycle again.

In this type of reflective practice, teachers afford children the opportunity to interpret concrete experience and internalise it in mental models that facilitate learning to represent abstract notions. One way of doing this is to use visual art as a vehicle or modality for children to represent their understandings of space and shape, which on the one hand are based on empirical experience, and on the other also abstract internal cognitive representations. According to Rushton and Larkin (2001:26), "the more multi-modal activities are, the more connections between 
lobes result". By this, we would argue, these authors mean activation of synapses in different parts of the brain. Finding different pathways and creating new mental models are also, in our view, a source of creativity.

A creative classroom should ideally provide opportunities for children to ask questions, generate their own ideas, draw conclusions, collaborate and co-construct also in their drawings of their understanding. Craft (2002; 2005) suggests the following teaching strategies for developing children's motivation to be creative: fostering indepth studies on topics of interest; stimulating and encouraging language; setting clear routines, which also involve children in ideas and structures; letting children go beyond the minimum requirements; allowing children to find relevance in activities; using alternative ideas in teaching and learning; encouraging alternative ways of being and doing; giving children time to incubate ideas; and allowing children to adopt different perspectives. Teaching for creativity should be focused on the learner: innovative contributions are valued, questions are encouraged and problems are identified, and opportunities are provided for debating and discussing. Children co-participate in an inclusive, creative learning environment (Craft 2002; 2005). All of these strategies bring together conceptual knowledge ('knowing that') and procedural knowledge (the 'how' of learning) (Craft 2005).

If, as we suggest, visual art is to be a tool for teaching about space and shape, then teachers need to understand the relationship between visual art and mathematics and must have the curriculum and pedagogical tools for implementing such an approach in their Grade R classrooms. Many artistic principles overlap with mathematical ones, for example, line, space, shape, measurement and pattern (Thomas \& Lindsay 2009). As explained by Piaget (1945), drawings form part of symbolic thought and are one of the ways in which the child uses symbols. Visual arts are a means of representing understanding and meaning (Hope 2008; Matthews 2006), and representing is an essential part of the learning process, because it entails identifying key spatial features in order to do it (Hope 2008).

Carruthers and Worthington (2006) and Matthews (2006) describe 'mark making' as one of the cultural tools that children use to represent their learning. It involves constructing meaning by making physical marks such as scribbles and drawings to represent thoughts. These spontaneous, self-initiated marks could be "physical pigment on a piece of paper, traces of light on a screen, or images on a liquid crystal display of a digital camera" (Matthews 2006:xiii).

The notion that certain schemas show children's movements in space and serve to represent their thoughts (Athey 2007) proposes that by observing children's representations of schemas through their mark making we are able to gain some insight into their understandings of space and shape.

'Schema' is a term used to describe a cognitive structure or system of concepts. According to Athey (2007), form is more important than content in the development of concepts. By this he means that the form of a schema takes precedence over the object it portrays. For instance, if a child is interested in drawing the sun (a circle), $s /$ he should be extended by learning about other circles in the environment, rather 
than only learning about the sun. However, Athey admits that it is not known how much experience is required for a new form to be constructed. What is known, is that the more diverse experiences a child has with a particular form, the more profound the conceptualization that will result (Athey 2007; Carruthers \& Worthington 2006; Worthington 2008).

Carruthers and Worthington (2006) describe their experiences of utilising the notion of schema to design further learning. They refer to the instance of a child who was passionate about spirals - drawing and cutting them out and often walking in spiral formations. Her mother made spiral cakes for the class to share. Gradually the rest of the class became interested in spirals too, and were allowed to explore spirals in different ways. With the teacher's support and mediation, this resulted in a plethora of activities around spirals: "[...] spirals and spiral-like marks appeared on paper, in painting and drawings. They embellished drawings as hair, fingers, sun and flowers; one shape within another, as patterns and as explorations of shapes" (Carruthers \& Worthington 2006:49).

In this instance, a teacher had observed the expression of a schema of one child and utilised this as a bridge to extend learning, including movement. Schemas are manifested in children's large muscle physical movements, but are also displayed in their drawings:

\begin{abstract}
Schemas can be described as a child's repeated pattern of behaviour; they cannot be taught as they come from the child's own self-interest; and when they are involved in a schema the level of children's involvement can be very intense. Some of this schematic thinking is represented in their drawings and form foundations for more complex structures and mathematical ideas. The schematic marks, like other mathematical mark-making, help bridge the gap between informal and formal mathematics. Supporting children's schemas feeds their natural curiosity which, in turn extends their thinking.
\end{abstract}

(Carruthers \& Worthington 2006:55)

Research suggests that creativity through the use of visual representation or mark making should be used cross-curricularly (Anning 2009; Brooks 2009; Craft 2002, 2005; Worthington 2008). This has particular implications for the learning of space and shape.

\title{
Research design and methods
}

The study was designed to capture and systematically describe the different understandings teachers bring to their experiences of Grade $\mathrm{R}$ teaching in terms of shape and space. Newby (2010), like qualitative methodologists in general, proposes that in-depth qualitative inquiry is aimed at eliciting the experiences and thinking of participants. At the outset of the research intervention, we assumed that the Grade $\mathrm{R}$ teachers, through a particular research intervention, could learn how to build a curriculum around their children's interests, and could express their learning in reflective practice mode. In terms of this assumed change of behaviour and practice, we thought it reasonable that they would be able to teach space and shape through visual arts experiences. The participants were twelve Grade $\mathrm{R}$ teachers enrolled for 
an in-service BEd (Foundation Phase) degree who had participated in the MStAC curriculum intervention. The majority were from rural and semi-rural no-fee schools or schools with fees of less than R150 per month.

The action research intervention took place over a period of six months. It followed a typical action research cyclic process (plan, develop, implement and evaluate), and built on what emerged during three contact sessions over the six-month period. The focus of each phase is shown in Figure 2. The two ribbons represent the teachers' learning and 'doing' (assignments, teaching and tasks with their own learners) during each phase.

Data were generated in each phase through course activities and assignments completed during the contact sessions, or at home between sessions, and consisted of reflective reports, completed task sheets, audiovisual recordings of group discussions, and photographs. As part of their coursework, the teachers were given assignments requiring them to make anecdotal notes when observing children, analyse these and write reflective reports; collect children's visual art work; and write essays. By the end of Phase III, they designed learning programmes around the schemas that they had observed the children portraying. 


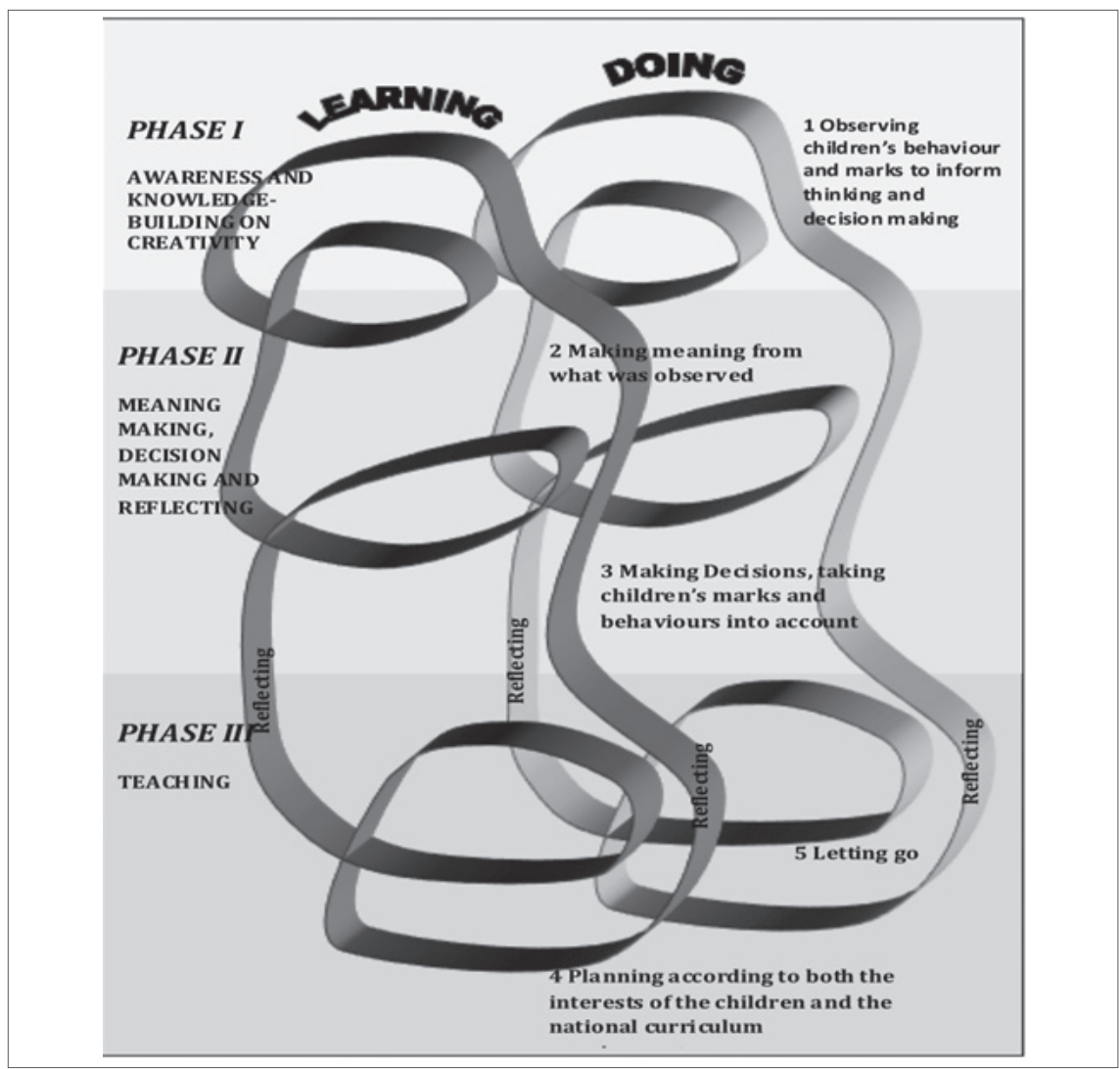

Figure 2: Steps towards a creative pedagogy (adapted from Stacey 2009:15)

\section{Discussion of the findings}

\section{Phase I: Awareness and knowledge building with regard to creativity}

The Grade $\mathrm{R}$ teachers who participated in the study were intent on following lessons produced by the Eastern Cape Department of Education (ECDE 2009), rather than building on the ideas and experiences that children brought with them to Grade $\mathrm{R}$. Phase I, therefore, aimed to develop the teachers' awareness and understanding of alternative ways of thinking about children's learning, their role as teachers, the concept of creativity, and how to observe children's behaviour and visual representations.

Data were generated through the teachers' oral and written responses to a DVD on promoting creativity and readings used during the contact session, the classroom observations of children that they undertook, the visual representations produced by the Grade $\mathrm{R}$ children they teach, and the reflective reports they wrote. 
The following responses and activities were noted and observed during Phase I:

- The teachers thought of creativity more in terms of the use of resources than of a classroom climate of encouragement and openness. We made the assumption that the teachers were experienced observers and did not provide an observation schedule. However, it was evident from the different observation approaches followed by the teachers that observing children's behaviours, interests and schemas was a new experience for many of them. In their reflections on the process of observation, many noted that it had made them more aware of what their learners were actually doing and saying during their informal play activities.

- The teachers collected examples of learners' visual representations, which, we argue, were authentic portrayals of different Grade R learners' behaviour, development and interests. These included children's free drawing and painting activities, and a few teachers brought worksheets as examples of visual art. These were categorized according to the schemas identified by Athey (2007) through observing 2125 action schemas of children. Athey grouped them into eight categories and then described them in terms of the motor level they signified, their symbolic representational level through drawings, their relationship to other functions, and the thoughts that these schemas provoked: dynamic vertical, dynamic back and forth, circular direction and rotation, going over, under or on top of, going round a boundary, enveloping and containing, going through a boundary, and thought (using many schemas to represent ideas).

In the reflective report, entitled An environment rich in learning opportunities, the teachers described how they had organized the environment in order to enable rich learning experiences to take place. They supported their descriptions with photographs of their learners engaged in activities in their learning environments. An analysis of these showed two focus areas in the teachers' descriptions of their learning environments: exposure to resources, and the teacher's role. This is illustrated in the following comments by participating teachers:

My classroom is a foundation of the early childhood curriculum. Each corner in my class is interesting and accessible, and rich in opportunities that motivate children to notice, ask questions and discover things in their world.

Others were convinced that resources are not that important:

A child needs no physical objects in order to create magnificent ideas. [S]ometimes there are teachers who don't teach children because of lack of resources, but there is no such thing [...] children can create something.

An awareness of children's prior learning experiences was expressed:

Learners come to school with a wealth of knowledge, ideas, opinions and skills which can be developed by the teacher by creating the environment rich in opportunities to learn.

Fleer (2010) suggests that teachers are inclined to believe that materials and resources do the teaching. She explains that, often, children are not necessarily 
learning what teachers intend them to learn when they have organized a particular learning scenario, for example, a shop or restaurant. It was interesting to note that many participating teachers understood their role as being more active than merely providing a learning environment. Ginsberg et al (2008:7) contend that a rich physical environment is not enough: "The crucial factor is not what the environment makes possible, but what the children do in it."

Siraj-Blatchford (2009:156) refers to Vygotsky's (Vygotsky 1978) notion of the 'zone of proximal development' as "sustained shared thinking", in which the (cognitive and general) 'distance' between the child's actual developmental level and what can result through problem-solving and collaboration.

According to Siraj-Blatchford (2009:156), Vygotsky's (1978) notion of the 'zone of proximal development' is a zone characterised by "sustained shared thinking" between a teacher and child. Through sustained shared thinking the distance between a child's actual developmental level and what can be achieved through problem solving and collaboration may be bridged. 'Conceptual play', as described by Fleer (2010), involves the teacher guiding and supporting children's learning in 'playful' activities that inflect their interest. Besides preparing the environment for children to learn, the teacher's role is to direct learning through questioning and to provide extended learning experiences that build on the conceptual learning taking place. We found that the participating teachers generally did not perceive themselves as 'co-collaborators' in the learning experiences of the children they were teaching.

- $\quad$ From the reports on three examples of scaffolding children's learning it was apparent that some teachers understood scaffolding as a process of helping a child who had learning problems, rather than engaging with a child and extending and enhancing learning in everyday situations.

Phase I formed the first part of an emergent curriculum framework. Phase II focused on making meaning of what the teachers had learned during Phase I.

\section{Phase II: Making meaning, making decisions and reflecting}

Phase II consolidated and extended the work of Phase I by incorporating pedagogical content knowledge, thus noting how content (knowing about how children learn through art and creative activity) is transformed into pedagogy, which is the central tenet of Shulman's theory of pedagogical content knowledge (Shulman 1987). It sought to develop the teachers' understanding and ability to make meaning of children's behaviour and visual representations using their knowledge of schemas; to make decisions about activities which would enhance and extend children's learning; and to reflect on the process of meaning making and decision making according to children's interests and behaviour.

Phase II, like Phase I, consisted of opportunities for both learning and 'doing'. The teachers worked collaboratively in groups to sort and classify the visual art activities they had collected into the different schemas and display them around the room. 
They consolidated and applied their learning through assignments completed at home after the contact session. The assignments required them to reflect on the experience of making meaning from observations and collections of schemas; implement activities they had planned in their groups during the contact session; and prepare a presentation on the implementation of the activities.

During Phase II the following was observed and noted by the researchers:

- The collections of visual art representations and the teachers' experiences of observing formed the foundation and stimulus for making (new) meaning of their pedagogical practice. Stacey (2009) maintains that taking the time to think about what children are portraying is a vital part of responding to their needs.

Athey (2007) describes how children's physical movements and drawings are closely related, because drawings are symbolic representations of their thought processes. Through their observations and the readings they had done, the teachers became aware of this close relationship. In focus groups, therefore, they made meaning of their observations and the children's schemas, and recorded this information on a task sheet. It was immediately apparent that worksheets were only able to demonstrate one type of schema - 'dynamic back and forth' - because often children were required to colour in rather than draw. It became clear to the teachers that it was not possible to understand the interests of children who were so limited in their representations.

The teachers showed how they 'made meaning' of the children's art by completing task sheets where they noted the interests of the children (through the children's schemas, as perceived by the teachers). During the contact sessions they collaborated on ways to enhance and extend those experiences further by sharing their observations. They were then required to write a reflective report on the process of making (new) meaning and to prepare a presentation for the following contact session on the activities they had implemented to extend the children's play interests.

- Many teachers made insightful suggestions about extending children's thinking and learning. For example, one child was fascinated by the schema 'going through a boundary' when she threaded all the holes in a peg board. Other children in her class became interested in this activity, so the teacher extended the schema by photocopying the threaded pegboard so that the other children could also thread their pegboards in the same way. In another instance, the teacher extended the 'enveloping and containing' schema by having her learners blow coloured bubbles through a straw for printing; and when this teacher saw a group of boys building a block tower, she encouraged them to go higher and higher, and later to explore 'going through a boundary' by dropping blocks through the tower from the top. One teacher observed learners positioning chairs in lines, rolling tyres, printing with wheels, and skipping with stockings and rope. The participants felt that all of these were examples of children's expression of the 'dynamic vertical' schema. 
One teacher extended this activity by helping the children arrange the chairs one behind the other, so that they could experience the feeling of sitting on a train.

However, it was clear that some of the teachers had not made the shift to allowing children to create their own representations and then to make meaning of them. One teacher described children drawing trees with apples falling as a 'dynamic vertical' schema. However, the photographs taken by the teacher to illustrate this revealed that the children were merely colouring in pre-drawn trees on a published worksheet. A worksheet like this does not allow children to express their own understandings or thinking by making their own marks (Carruthers \& Worthington 2006).

- An analysis of the teachers' reflective reports on the meaning-making process revealed that they had became aware that children's drawings and representations on paper can influence planning; that they had developed an increased awareness of children's behaviour and drawings; and that their view of the teacher's role was changing, so that they engaged more with their learners in mediating learning. Evidence from their responses suggested that they were developing an understanding of the 'emergent curriculum' process and of how planning in this way could help them to become more effective teachers. The teacher dispositions identified by Stacey (2009:15), that is, "teachers in relationship with the child, parents and community", "collaboration with the child", and "teacher as researcher, child as protagonist", were becoming apparent in the teachers' reflections. One participant commented as follows:

Mark making is the child's way of formulating ideas, expressing themselves and processing their perceptions of their worlds. By making marks, they can create evidence of their thoughts.

\section{Phase III: Teaching space and shape}

Subject matter knowledge is seen as an essential aspect of teaching (Borko \& Putnam 1995; Silverman \& Thompson 2008). With this in mind, Phase III involved the teachers learning more about space and shape, and how to teach it in their Grade $\mathrm{R}$ classes. The general pedagogical knowledge and pedagogical content knowledge from Phases I and II were further developed in Phase III, during which the teachers applied what they had learned to actual mathematics teaching about the concepts of space and shape using visual arts activities.

During the contact session, the teachers learned about the development of spatial conceptualization in young children, how the Van Hiele levels (Ryan \& Williams 2007) apply to teaching, and about space and shape in their classrooms (see Diagram 1). Some isiXhosa speakers realized that they were not familiar with the names of certain shapes in their mother tongue, as they used the English names for shapes even when they were teaching in isiXhosa. The teachers formed groups according to the language in which they taught, and researched shape names in isiXhosa and Afrikaans. 
In order to develop a deeper understanding of space and shape and to better appreciate their learners' engagement with space and shape, the teachers then performed a number of spatial and shape tasks, which they were required to reflect upon. Although many of the teachers used these shape and space games in their classrooms, it was obvious that they had little experience of 'doing' (playing) them. It also became evident that many teachers had little, if any, experience in basic drawing.

Phase III's assignment involved the teachers planning lessons on space and shape, using the subject knowledge they had gained during Phase III, around their learners' interests, that is, the representations of schemas they had observed and made meaning of in Phases I and II.

The following was observed and noted by the researchers during Phase III:

- All the teachers described the behaviour and interests of their learners and showed how the lessons they planned were aimed at extending the children's interests and learning. Most of the participants planned interesting lessons on shape and space using different resources, including, for example, feely bags. Many teachers planned an entire theme around an aspect of shape, for example, boxes or circles, with many different activities taking place over the course of a week. However, some visual arts activities were not creative, in that the children were not free to make what they wanted to make, for example, a pair of binoculars from two toilet rolls. Certain visual arts activities could have been more creative by allowing the children more choices and allowing them to create their own meanings and expressions of understanding, rather than, for example, having them use pre-cut shapes to form a particular picture. Some teachers demonstrated innovative ways of helping their learners move from the concrete to the abstract, for example, giving them a box stuck to card and allowing them to use their imagination to turn the shape into something. Overall, their reflections on their space and shape lessons showed that the teachers were becoming skilled at using an emergent curriculum process, recognizing children's interests, and allowing them to make their own meanings.

At first, it was evident that, as Carruthers and Worthington (2006:34) argue, teachers often appear to view creativity in mathematics in terms of "specific resources or activities, rather than processes". Far more than merely providing resources and activities that make learning fun, teachers should set clear goals for learning, have the ability to balance freedom and constraint, expect the unexpected, and use language to stimulate creativity (Craft 2002; 2005). Einarsdottir et al (2009) explain that children's drawings convey their understandings, and thus it is vital that young children have access to a range of materials and resources as well as an appropriate ambience for meaning making. They also recommend that children's graphics should be seen as intentional, purposeful meaning making.

- Generally, the lessons and activities planned and implemented by the teachers were a direct response to the behaviour, interests and schemas that they had observed. 
This suggests that the participating teachers were gaining more confidence to design learning programmes consistent with the interests of the children they teach. Moon and Leach (2008:17) refer to teachers and children negotiating an "authentic curriculum". This requires a close relationship between teachers, children and families. Teachers should be aware of children's interests, and this awareness results from observing them closely. Many of the participating teachers admitted that they had not closely observed children before, and consequently, they mostly observed when they were assessing their performance in particular tasks. Often their comments related more to what the child could not do rather than what the child could do, from which one may infer a form of observation characteristic of a behaviourist approach. On the other hand, those teachers who took continuous anecdotal notes were more curious about the children's interests and behaviour and paid attention to their drawings and speech. This type of observation is consistent with a social constructivist approach.

- The teachers remarked that they had become more aware of their learners' behaviour, interests and drawings, and could use this knowledge to enhance their planning. As the teachers observed, made meaning, made decisions and planned around children's interests, the desirable dispositions for teachers - curiosity, collaboration and reflection (Stacey 2009:15) - became more evident. By having to reflect as part of the emergent curriculum process, the teachers were forced to think more deeply about their roles as teachers and mediators of learning.

In the next section we respond to the question: What lessons can be learned from this intervention?

\section{Lessons learned in the action research intervention}

As a case study with a small group of teachers in a particular context, the study has limitations. Although the group was diverse, with teachers from a range of schools and backgrounds that reflect some of the demographics of South Africa, the study may not be applicable to other Grade R teachers in South Africa. Notwithstanding these limitations, we contend that there are lessons to be learned from our action research intervention that can stimulate further debate around Grade $\mathrm{R}$ teaching and how young children learn space and shape though visual art. The study may also have implications for teacher professional development in action research format.

\section{Teachers of Grade R children should be afforded the opportunity to learn how to cultivate creative environments for children.}

This study revealed that the participating teachers did not have a clear understanding of creativity, nor of how to effectively plan their pedagogy with the creative expression of children in mind. Teachers need to learn more about their role in classroom interaction, one that is aimed at mediating and scaffolding the creative expression of children, as suggested by Craft (2002; 2005). Teachers also need professional 
nourishment in the form of personal and professional development in order to design a creative learning environment (Craft 2002). Teacher development programmes should therefore explore the nurturing of creativity in Grade $\mathrm{R}$ children and also encourage professional communities that (creatively) support and collaborate with each other.

\section{More guidance should be given on teaching visual arts with children's creativity in mind.}

Consistent with the idea of merely exposing children to resources, some teachers considered the provision of art media such as crayons, paper and paint sufficient for visual arts to result. They did not consider themselves as having an active role in encouraging children's expressions of meaning. Children's expressions of meaning go hand in hand with a creativity-oriented learning environment. Teachers need guidance on the purpose of visual arts activities as children's expressions of meaning (and also search for meaning) in such an environment.

\section{Observation of children's behaviour and interests is a skill that should be} practiced more widely by Grade $R$ teachers.

Being aware of the interests (and schemas) that children display can help teachers to make meaning of their behaviour and plan accordingly by incorporating the children's interests into the curriculum. Fleer (2010) explains that children learn more competently when their interests are included in the learning programme. From this perspective, it holds that an awareness of the meanings of children's schemas (as expressed in visual art) can also help to deepen teachers' understanding of children's interests. A helpful approach would be for teachers to use anecdotal note-taking techniques, rather than merely remarking on behaviour and applying deficit models of performance to the children they teach.

\section{Grade $R$ children should have a variety of materials and media available for expressing themselves through 'mark making'.}

Many Grade R children do not have sufficient opportunities to express themselves through mark making. Sometimes the reason for this resides in a lack of resources; at other times it is because the curriculum does not make the time or resources available for the free expression that is required. Planning should therefore take into account the need for young children to draw, paint, model, cut and paste.

\section{Grade $R$ teachers should be given guidance on how to critically analyse published lesson plans and worksheets.}

With the plethora of published lesson plans and worksheets available, teachers are prone to using them uncritically, without questioning whether or not they are appropriate for their own contexts. Generic lesson plans published on the Internet are often used indiscriminately, even though the context for which they were planned may be entirely different. Because of teachers' acceptance of 'top-down' rules and 
regulations concerning curricula, they use them without asking what the lessons and worksheets are teaching, or how children will be able to express their own understandings using such materials. This alludes to the confidence of teachers in their own abilities to plan curricula around the interests of children, and relates closely to teachers being reflective practitioners who are able to plan around the needs of the children whom they teach.

\section{Grade $R$ teachers need more experience of performing space and shape activities themselves.}

The space and shape tasks that the teachers engaged in during Phase III revealed that many of them had had little experience with space and shape problem solving before. In our view, teachers would feel more comfortable teaching concepts such as space and shape if they themselves engaged in tasks such as the ones offered during the Phase III contact session. They would also then be more inclined to offer such activities to their learners. The fact that the majority of participants avoided certain tasks, for example, drawing, and expressed fear of this activity, reveals a lack of experience and confidence regarding the concepts of space and shape.

\section{Teachers should know the appropriate terminology for the properties of shapes in the language of instruction.}

In order to develop deep conceptual understanding, which will enable them to progress through the Van Hiele levels of geometric understanding, Grade R children should be taught vocabulary around the properties of shape and space and be able to use these words and understandings (Clements \& Battista 1992; Ryan \& Williams 2007). This view is consistent with research that shows that children learn concepts best if they are taught in their mother tongue. It is therefore vital that Grade $\mathrm{R}$ teachers teach children the correct terminology in their home language. This does not preclude them from also teaching the English variants, thereby establishing an important link for when learners are eventually taught through the medium of English (Henning 2012).

\section{Grade $R$ teachers should have exposure to many ideas and suggestions for interesting visual arts activities, using a variety of media, and be allowed to experience them before implementation in the classroom.}

Generally, teachers tend to present the same visual arts activities that they have used many times before. Even though the teachers who had participated in the initial intervention that formed the background to this study had been provided with manuals of suggested activities, they did not use them. Perhaps, if they were allowed to experience these activities beforehand, teachers would feel more confident about presenting them to children. An example is the doily-cutting task, which some teachers had not tried before, but presented to their classes after experiencing it at the contact session. 
9. Grade $R$ teachers should be provided with more guidance regarding their role as teachers of content and skills and facilitators of learning.

In the authors' view, Grade R teachers often tend to see their role as a passive one. They provide the learning environment and then scaffold learning as the children learn through discovery. Fleer (2010) describes a more structured play environment, where questioning is directed around the concepts that the teacher wants the children to learn. Ginsburg et al (2008) also explain that the teacher's role is an active one, noting that "teaching mathematics to little children is as complex and challenging as is teaching it to older children" (ibid:284).

\section{Conclusion: Grade $\mathbf{R}$ teachers and focused action research}

At the outset of the research, we became aware of the dearth of research available in the areas of Grade R curriculum and pedagogy, Grade R teacher professional development, and early years mathematics teaching, especially in the context of South Africa. Ginsburg and Amit (2008) and Ginsburg et al (2008) remind us that little is known about early years mathematics teaching. They go on to recommend extensive in-service training and support programmes for early years teachers, as well as more research into learning potential in children, teacher knowledge, teaching, and assessment and evaluation methods in order to improve mathematics teaching.

Our research provides some understanding of Grade $\mathrm{R}$ teacher professional development, Grade $\mathrm{R}$ mathematics teaching in the area of space and shape, and Grade R curriculum and pedagogy within the context of South Africa. It also makes evident the inadequacies in teachers' mathematical knowledge and pedagogy. We have explained how a curriculum intervention in an in-service teacher education programme was developed to support teachers with regard to the use of visual art to teach space and shape in Grade R classrooms. Fairbanks, Duffy, Faircloth et al (2009:161) argue that teachers require more than professional knowledge about teaching in order to become "thoughtfully adaptive", and suggest that 'thoughtfully adaptive' teachers have a vision and seek to do more than merely impart curriculum knowledge. We hope that the lessons learned from this research intervention may offer other teacher educators some guidelines on how to facilitate the development of 'thoughtfully adaptive' teachers who are curious and collaborative, and who understand how visual arts can support and enhance young children's mathematical learning.

\section{References}

Anning, A. 2009. The co-construction of an Early Childhood curriculum. In: A. Anning, J. Cullen \& M. Fleer (Eds). Early Childhood education: Society and culture. London: Sage. 67-79.

Athey, C. 2007. Extending thought in young children: A parent-teacher partnership. London: Paul Chapman Publishing. 
Berk, L.E. \& Winsler, A. 1995. Scaffolding: Vygotsky and early childhood. Washington DC: National Association for the Education of Young Children (NAEYC).

Berk, L.E. 2006. Child development. $7^{\text {th }}$ Edition. London: Pearson. Retrieved from http:// www.ablongman.com/html/productinfo/berkcd7e/0205449131.pdf (accessed 26 September 2009).

Borko, H. \& Putnam, R.T. 1995. Expanding a teacher's knowledge base: A cognitive psychological perspective on professional development. In: T.R. Guskey \& M. Huberman (Eds). Professional development in education: New paradigms and practices. New York: Teachers College Press. 35-65.

Brooks, M. 2009. Drawing, visualization and young children's exploration of 'Big Ideas.' International Journal of Science Education, 31(3):319-341.

Carruthers, E. \& Worthington, M. 2006. Children's mathematics: Making marks, making meaning. London: Paul Chapman.

Clements D.H., Swaminathan, S., Hannibal, M.A.Z. \& Sarama, J. 1999. Young children's concepts of shape. Journal for Research in Mathematics Education, 30(2):192-212.

Clements, D.H. \& Battista, M.T. 1992. Geometry and spatial reasoning. In: D.A. Grouws (Ed). Handbook of research on mathematics teaching and learning. New York: Macmillan. 420-464.

Craft, A. 2002. Creativity and early years education. Alifewide foundation. London: Continuum.

Craft, A. 2005. Creativity in schools: Tensions and dilemmas. Oxford: Routledge.

Dehaene, S. \& Brannon, E.M. 2011. Foreword. In: S. Dehaene \& E.M. Brannon (Eds). Attention and Performance. Volume 24. Space, time and number in the brain. Searching for the foundations of mathematical thought. Oxford: Oxford University Press. ix-xii.

Dillon, M.R., Huang, Y. \& Spelke, E.S. 2013. Core foundations of abstract geometry. Proceedings of the National Academy of Sciences, 110:14191-14195.

ECDE (Eastern Cape Department of Education). 2009. Grade $R$ lesson plans. Retrieved from http://ecdfoundationpahse.250free.com/2009\%20T2\%20GRADE $\% 20$ R\%20 LESSON\%20PLANS.pdf (accessed 21 October 2010).

Einarsdottir, J., Dockett, S. \& Perry, B. 2009. Making meaning: Children's perspectives expressed through drawings. Early Child Development and Care, 179(2):217-232.

Engeström, Y.1987. Learning by expanding: An activity-theoretical approach to developmental research. Helsinki: Orienta-Konsultit.

Engeström, Y. 1999. Activity theory and social and individual transformation. In: Y. Engeström, R. Miettenen \& R. Punamaki (Eds). Perspectives on Activity Theory. New York: Cambridge University Press. 19-38.

Engeström, Y. 2007. Putting Vygotsky to work: The change laboratory as an application of double stimulation. In: H. Daniels, M. Cole \& J.V. Wertsch (Eds). The Cambridge companion to Vygotsky. New York: Cambridge University Press. 363-382. 
Fairbanks, C.M., Duffy, G.G., Faircloth, B.S., He, Y., Levin, B., Rohr, J. \& Stein, C. 2009. Beyond knowledge: Exploring why some teachers are more thoughtfully adaptive than others. Journal of Teacher Education, 61(1-2):161-171.

Fleer, M. 2010. Early learning and development: cultural historical concepts in play. New York: Cambridge University Press.

Gelman, R. \& Butterworth, B. 2005. Number and language: how are they related? Trends in Cognitive Sciences, 9(1):6-10.

Gifford, S. 2005. Teaching mathematics 3 - 5: Developing learning in the Foundation Stage. London: Open University Press.

Ginsburg, H.P. \& Amit, M. 2008. What is teaching mathematics to young children? A theoretical perspective. Journal of Applied Developmental Psychology, 29:274-285.

Ginsburg, H.P., Lee, S.J. \& Stevenson-Boyd, J.S. 2008. Mathematics education for young children: What it is and how to promote it. Social Policy Report. Society for Research in Child Development. Retrieved from http://files.eric.ed.gov/fulltext/ ED521700.pdf (accessed 12 August 2014).

Hargreaves, A. 1995. Development and desire: A postmodern perspective. In: T. Guskey \& M. Huberman (Eds). Professional development in education: New paradigms and practices. New York: Teachers College Press. 9-34.

Hedegaard, M. 2007. The development of children's conceptual relation to the world with focus on concept in pre-school children's activity. In: H. Daniels, M. Cole \& J.V. Wertsch (Eds). The Cambridge companion to Vygotsky. New York: Cambridge University Press. 246-275.

Henning, E. 2012. Learning concepts, language and literacy in hybrid linguistic codes: The multilingual maze of urban grade 1 classrooms in South Africa. Perspectives in Education, 30(3):69-78.

Hope, G. 2008. Thinking and learning through drawing in primary classrooms. London: Sage.

Lee, S.A., Sovrano, V.A. \& Spelke, E.S. 2012. Navigation as a source of geometric knowledge: Young children's use of length, angle, distance, and direction in a reorientation task. Cognition 123, 144-161.

Lunenberg, M. \& Korthagen, F. 2009. Experience, theory and practical wisdom in teaching and teacher education. Teachers and Teaching: theory and practice, 15(2):225-240.

Matthews, J. 2006. Foreword. In: E. Carruthers \& M. Worthington (Eds). Children's mathematics: Making marks, making meaning. London: Paul Chapman. xiii-xiv.

Mena Marcos, J.J., Sánchez, E. \& Tillema, H. 2008. Teachers reflecting on their work: articulating what is said about what is done. Teachers and Teaching: theory and practice, $14(2): 95-114$.

Mevarech, Z.R. 1995. Teachers' paths on the way to and from the professional development forum. In: T. Guskey \& M. Huberman (Eds). Professional development in education: New paradigms and practices. New York: Teachers College Press. 151-170.

Moon, B. \& Leach, J. 2008. The power of pedagogy. London: Sage. 
NAEYC (National Association for the Education of Young Children). 1996. Developmentally appropriate practice in Early Childhood programs serving children from birth through age 8. A position statement of the National Association for the Education of Young Children. Washington, DC: NAEYC.

Newby, P. 2010. Research methods for education. London: Longman.

Piaget, J. \& Inhelder, B. 1967. The child's conception of space. London: Routledge and Kegan Paul.

Piaget, J. 1945. Play, Dreams and Imitation in Childhood. New York: Norton.

Pound, L. 2003. Supporting mathematical development in the early years. Buckingham: Open University Press.

Rushton, S. \& Larkin, E. 2001. Shaping the learning environment: Connecting developmentally appropriate practice to brain research. Early Childhood Education Journal, 29(1):25-33.

Ryan, J. \& Williams, J. 2007. Children's mathematics 4 - 15: Learning from errors and misconceptions. Buckingham: Open University Press.

Schäfer, J. 2009. Maths and Science through the Arts and Culture Programme. Unpublished evaluation report. The Curriculum Development Project for Arts and Culture Education and Training (CDP). Grahamstown: Rhodes University.

Schäfer, J. 2010. An investigation of how visual arts can be used to teach mathematical concepts of space and shape in grade R. Unpublished MA thesis. Grahamstown: Rhodes University.

Schulman, L. 1987. Knowledge and teaching: foundations of the new reform. Harvard Educational Review, 57(1):1-21.

Silverman, J. \& Thompson, P.W. 2008. Toward a framework for the development of a mathematical knowledge for teaching. Journal of Mathematics Teacher Education, 11:499-511.

Siraj-Blatchford, I. 2009. Quality teaching in the early years. In: A. Anning, J. Cullen \& M. Fleer (Eds). Early childhood education: Society and culture. London: Sage. 147-157.

Spelke, E.S. \& Kinzler, K.D. 2008. Core knowledge. Developmental Science, 10:89-96.

Spelke, E.S. \& Lee, S.A. 2012. Core systems of geometry in animal minds. Philosophical Transactions of the Royal Society, B367:2784-2793.

Spelke, E.S. 2003. Developing knowledge of space: Core systems and new combinations. In: S.M. Kosslyn \& A. Galaburda (Eds). Languages of the Brain. Cambridge, MA: Harvard University Press. 239-258.

Spelke, E.S. 2011a. Core systems and the growth of human knowledge: Natural geometry. In: A.M. Battro, S. Dehaene \& W.J. Singer (Eds). The Proceedings of the Working Group on Human Neuroplasticity and Education. Volume 117. Human Neuroplasticity and Education. Vatican City, Italy: The Pontifical Academy of Sciences. 73-99. 
Spelke, E.S. 2011. Natural number and natural geometry. In: E. Brannon \& S. Dehaene (Eds). Attention and Performance. Volume 24. Space, time and number in the brain. Searching for the foundations of mathematical thought. Oxford, United Kingdom: Oxford University Press. 287-317.

Stacey, S. 2009. Emergent curriculum in early childhood settings: From theory to practice. St Paul, MN: Redleaf Press.

Thomas, D. \& Lindsay, V. 2009. Maths and Science programmes through Arts and Culture in ECD/Grade R curricula. Johannesburg: Curriculum Development Project.

Vygotsky, L.S. 1978. Mind and society. Cambridge: Harvard University Press.

Wilmot, P.D. 2005. Teachers as recontextualisers: A case study analysis of outcomesbased assessment policy implementation in two South African schools. Unpublished PhD thesis. Grahamstown: Rhodes University.

Worthington, M. 2008. Children's mathematical graphics: Overview. Retrieved from http:// www.childrens-mathematics.net/overview.pdf (accessed on 12 August 2014).

Zeichner, K.M. \& Liston, D.P. 1996. Reflective teaching. An introduction. New Jersey: Lawrence Erlbaum.

\section{Endnotes}

i. The first author is the teacher educator who designed and undertook the research, and the second author is an academic who helped to conceptualise and supervise the study. 